\title{
Notation Cultures: Towards an Ethnomusicology of Notation
}

\author{
FLORIS SCHUILING
}

\section{Is music notation musical?}

IN the various arguments for a more diverse, social and ethical musicology that have been made in the past 30 years, a central contention has been that the score is not (the) music. A music scholarship that identified music with musical writing was seen to bypass the practical, creative and social processes that are involved in making and listening to music, and moreover to render theoretically and methodologically secondary the cultural contexts in which such processes take place. Nicholas Cook argued that the 'ocularcentric identification of the score with what the music is' turned music into an 'esoteric form of literature', distorting our views on music history, aesthetics and performance. ${ }^{1}$ Notation reifies, essentializes, disciplines; according to Philip Bohlman, it 'becomes a convenient way of collapsing time and space, thereby removing all sorts of Others - Western and non-Western - to the plane of the universal'. ${ }^{2}$

Although such arguments have done important work to change the scope, methods and aims of music scholarship, I find problematic the way in which this perspective seems only to perpetuate the long-standing discourse that considers music notation to stand outside the cultural processes that we study, and does not see it as an object of social and creative interaction in its own right. As Emma Dillon has observed: 'Writers from Isidore of Seville to Ingarden suggest a drastic distinction between inscription and performance: music exists in sound, and writing [...] is a representation removed

\section{Email: f.j.schuiling@uu.nl}

Research for this article was supported by a Veni grant from the Netherlands Organization for Scientific Research (NWO). Earlier versions were presented at the Performing Indeterminacy Conference in Leeds in 2017 and at the Comparative Literature Seminar at Utrecht University in 2017. I wish to thank Nicholas Cook, Kyle Devine, Derk van de Hulst and Susan Rankin for their comments on the first draft of this article.

${ }^{1}$ Nicholas Cook, 'Making Music Together, or Improvisation and its Others', Music, Performance, Meaning: Selected Essays (Aldershot: Ashgate, 2007), 321-41 (p. 337).

2 Philip Bohlman, 'Musicology as a Political Act', Journal of Musicology, 11 (1993), 411-36 (p. 424).

(C) 2019 The Author(s). Published by Informa UK Limited, trading as Taylor \& Francis Group.

This is an Open Access article distributed under the terms of the Creative Commons Attribution-NonCommercialNoDerivatives License (http://creativecommons.org/licenses/by-nc-nd/4.0/), which permits non-commercial re-use, distribution, and reproduction in any medium, provided the original work is properly cited, and is not altered, transformed, or built upon in any way. 
from musical reality. ${ }^{3}$ David Tudor once said, 'There is a paragraph in Busoni which speaks of notation as an evil separating musicians from music, and I feel everyone should know that this is true.' ${ }^{4}$ There is a hint in such comments of what Jonathan Sterne has called the 'audio-visual litany', positing the aural experience of music as more authentic and truthful than one mediated by vision. ${ }^{5}$ As he argues, aurality has its own history of mediation. Considering the significance of notation for the construction of musical knowledge, creativity and culture in many different musical practices in the world and throughout history, notation might be seen as one of the ways in which aurality has been mediated. To be sure, such long-standing and widespread ideas of notation being removed from musical reality cannot simply be dismissed as ideological, but the idea that notation is simply 'unmusical' fails to account for its importance.

In this article I propose a framework that views such processes of signification and representation as an integral and important part of our 'musicking' behaviour. ${ }^{6}$ The idea of an 'ethnomusicology of notation' is intended as a counterpoint to the 'musicology of performance' and its attempt to blur traditional boundaries between musicology and ethnomusicology in favour of a broad investigation of the relation between music and what it means to be human. ${ }^{7}$ An 'ethnomusicology of notation' signifies a broadly anthropological perspective on the social, epistemic and creative processes involved in practices of writing and reading music, instead of a narrowly musicological or music-theoretical one, which would study notation mainly for its musical content. The ethnomusicology I refer to is the approach which Frank Harrison famously said that it was 'the function of all musicology to be'. ${ }^{8}$ History is integral to

3 Emma Dillon, 'Music Manuscripts', Cambridge Companion to Medieval Music, ed. Mark Everist (Cambridge: Cambridge University Press, 2011), 291-319 (p. 291).

${ }^{4}$ Quoted in David Cline, The Graph Music of Morton Feldman (Cambridge: Cambridge University Press, 2016), 289.

5 Jonathan Sterne, The Audible Past: Cultural Origins of Sound Reproduction (Durham, NC: Duke University Press, 2003), 15-19.

${ }^{6}$ Christopher Small, Musicking: The Meanings of Performing and Listening (Middletown, CT: Wesleyan University Press, 1998).

7 Nicholas Cook, 'We Are All (Ethno)musicologists Now', The New (Ethno)musicologies, ed. Henry Stobart (Plymouth: Scarecrow Press, 2008), 48-70; Georgina Born, 'For a Relational Musicology: Music and Interdisciplinarity, Beyond the Practice Turn', Journal of the Royal Musical Association, 135 (2010), 205-43; Gary Tomlinson, 'Musicology, Anthropology, History', The Cultural Study of Music: A Critical Introduction, ed. Martin Clayton, Trevor Herbert and Richard Middleton, 2nd edn (New York: Routledge, 2012), 59-72; Cook, Beyond the Score: Music as Performance (Oxford: Oxford University Press, 2013).

8 Quoted in Cook, 'We Are All (Ethno)musicologists Now', 65. See also John Blacking, How Musical Is Man? (Seattle, WA: University of Washington Press, 1973); Kay Kaufman Shelemay, 'Crossing Boundaries in Music and Musical Scholarship: A Perspective from Ethnomusicology', Musical Quarterly, 80 (1996), 13-30; Laudan Nooshin, 'Introduction to the Special Issue: The Ethnomusicology of Western Art Music', Ethnomusicology Forum, 20 (2011), 285-300. 
my argument, as many of my examples below draw on historical studies of notation. ${ }^{9}$ Still, although this approach is not necessarily characterized as the ethnographic study of notational practices, one of my primary aims is to advocate such research, which remains very scarce, partly because of the traditional assumption that musicology studies the history of literate Western art music while ethnomusicology studies the music of oral others.

Rather than a 'Great Divide' between oral and literate society, when we look at contemporary musics we encounter what Susan Rankin, speaking of the earliest notations in Europe, has called a 'heterogeneous chaos'. ${ }^{10}$ Musicians today variously use notation systems ranging from mensural notation to computer code, from guitar tablature to graphic scores, from jianpu to drum bols, and from piano-roll style MIDI visualizations to shape-note music. In all these different practices, notations serve to construct forms of musical interaction. They mediate performed identities, and inform notions of music as a cultural practice. They offer different ways of imagining sound as music, make different demands on musical knowledge, and condition musicians' creative agency. In short, they construct notation cultures. However, it is difficult to address these functions because the traditional concept of notation in music scholarship is methodologically at odds with studying performance in the first place.

As the visual culture scholar W. J. T. Mitchell points out, 'Pictures are a popular political antagonist because one can take a tough stand on them, and yet, at the end of the day, everything remains pretty much the same. Scopic regimes can be overturned repeatedly without any visible effect on either visual or political culture.' 11 Instead of the impossible aim of destroying images, Mitchell proposes, drawing on Nietzsche, to 'sound out' the idols, not to break them with a hammer but to play them with a tuning fork, thus 'breaking [their] silence, making [them] speak and resonate, and transforming [their] hollowness into an echo chamber for human thought'. ${ }^{12}$ Have musicians playing from notation not always been engaged in such a 'sounding out' of the idols of musical notations, creatively negotiating the various social and technological mediations that make the existence of these works possible? Perhaps we can seek the answer to the question of notation's musicality not in its representation of musical structures, but in its mediation of the social and creative agency of musicians. Such an approach would suspend the critical impulse aiming to unveil true reality behind the appearances that have deceived us for so long, and

9 Anthropological and ethnomusicological perspectives have long informed histories of notation, the most explicit example of which is probably Peter Jeffery, Re-envisioning Past Musical Cultures: Ethnomusicology in the Study of Gregorian Chant (Chicago, IL: University of Chicago Press, 1992).

10 Quoted in Leo Treitler, With Voice and Pen: Coming to Know Medieval Song and How It Was Made (Oxford: Oxford University Press, 2003), 328.

11 W. J. T. Mitchell, What Do Pictures Want? The Lives and Loves of Images (Chicago, IL: University of Chicago Press, 2005), 33.

12 Ibid., 27. 
instead study what Bruno Latour - with an appropriate metaphor - has called the 'compositional' process of building a common world by drawing things together while retaining their heterogeneity. ${ }^{13}$

To address the compositional work of notation, I define notations as interfaces for imagining virtual musical relations. My choice of the term 'interface' aims to avoid a binary distinction between text and performance by embedding notation in a wider ecology of technologies and practices. An important step towards the musicology of performance was the reconsideration, by Cook, of the score as a 'script' for musicians' interaction. ${ }^{14}$ In science and technology studies, technologies are similarly said to contain 'scripts' that enable their users to achieve successful interaction. ${ }^{15}$ Scores may be understood to contain 'scripts' (in Cook's sense) for performing the music represented by them, but also (as technologies) for using and reading the notation two categories that may bleed into each other. Already, then, we can see that notation mediates the behaviour of its users on multiple levels. Lucy Suchman, in an important early investigation on human-machine interaction, critiques the view that 'treats a plan as a sequence of actions designed to accomplish some preconceived end', and advocates instead a view of situated action, which is necessarily improvisatory and the organization of which is emergent in ongoing practice. ${ }^{16}$ Plans or interfaces are not models of these practices, but rather 'resources for action' that can be used to reflect on earlier actions or to open up new possibilities. As Branden Hookway argues, interfaces are best understood not as technological objects, but in terms of the quality of the relations between humans and technologies which they construct. ${ }^{17}$

In a critical commentary on the performative turn, Ian Pace writes that he sees scores 'as the means for channelling performers' creative imagination in otherwise unavailable directions, rather than as an obstacle'. ${ }^{18}$ The imaginative effects of notation are central to the formation of notation cultures. We may consider notations as 'technologies of the imagination', in the sense described by the anthropologists David Sneath, Martin

13 Bruno Latour, 'An Attempt at a "Compositionist Manifesto"', New Literary History, 41 (2010), 471-90; see also Latour, 'Why Has Critique Run Out of Steam? From Matters of Fact to Matters of Concern', Critical Inquiry, 30 (2004), 225-48.

${ }^{14}$ Nicholas Cook, 'Between Process and Product: Music and/as Performance', Music Theory Online, 7 (2001), <http://www.mtosmt.org/issues/mto.01.7.2/mto.01.7.2.cook.html> (accessed 8 March 2019).

15 Madeleine Akrich and Bruno Latour, 'A Summary of a Convenient Vocabulary for the Semiotics of Human and Nonhuman Assemblies', Shaping Technology / Building Society: Studies in Sociotechnical Change, ed. Wiebe E. Bijker and John Law (Cambridge, MA: MIT Press, 1992), 259-64.

16 Lucy Suchman, Human-Machine Reconfigurations: Plans and Situated Actions, 2nd edn (Cambridge: Cambridge University Press, 2007), 52.

17 Branden Hookway, Interface (Cambridge, MA: MIT Press, 2014).

18 Ian Pace, 'The New State of Play in Performance Studies', Music and Letters, 98 (2017), 281-92 (p. 285). 
Holbraad and Morten Axel Pedersen, which 'serve to precipitate outcomes that they do not fully condition'. ${ }^{19}$ As Marilyn Strathern puts it:

Culture consists in the way analogies are drawn between things, in the way certain thoughts are used to think others. Culture consists in the images which make imagination possible, in the media with which we mediate experience. All the artefacts we make and the relationships we enter into have in that sense 'cultural' consequences, for they give form and shape to the way we think about other artefacts, other relationships. ${ }^{20}$

Cook proposes a remarkably similar understanding of a musical culture, which he defines as 'in essence, a repertoire of means for imagining music'. ${ }^{21}$ In his work on musical multimedia, he rephrases this definition: 'Musical cultures are not simply cultures of sounds, not simply cultures of representations of sounds, but cultures of the relationship between sound and representation.'22

Other elements of the definition will be discussed throughout this article. I will organize the following discussion around three distinct concepts: mobilization, entextualization and remediation. These three concepts, which will be discussed in more detail below, are drawn respectively from science and technology studies, linguistic anthropology and media studies, but I draw more broadly throughout on an interdisciplinary concern for the materiality of writing and reading. ${ }^{23}$ The first category

19 David Sneath, Martin Holbraad and Morten Axel Pedersen, 'Technologies of the Imagination: An Introduction', Ethnos, 74 (2009), 5-30 (p. 25).

20 Marilyn Strathern, Reproducing the Future: Essays on Anthropology, Kinship and the New Reproductive Technologies (Manchester: Manchester University Press, 1992), 33. Philippe Descola has taken this focus on analogies much further, making clear its vast ontological and moral implications. See Descola, Beyond Nature and Culture (Chicago, IL: University of Chicago Press, 2013).

21 Nicholas Cook, Music, Imagination, and Culture (Oxford: Oxford University Press, 1990), 4.

22 Nicholas Cook, Analysing Musical Multimedia (Oxford: Clarendon Press, 1998), 270.

23 This concern emerged partly from Jacques Derrida's grammatological work, but particularly from Katherine Hayles's post-human literary criticism and Friedrich Kittler's work on Aufschreibesysteme or 'notation systems'. See Jacques Derrida, Of Grammatology, trans. Gayatri Chakravorty Spivak (Baltimore, MD: Johns Hopkins University Press, 1976), N. Katherine Hayles, Writing Machines (Cambridge, MA: MIT Press, 2002) and Friedrich A. Kittler, Discourse Networks 1800/1900, trans. Michael Metteer (Stanford, CA: Stanford University Press, 1990). For representative examples, see among others Timothy Lenoir, Inscribing Science: Scientific Texts and the Materiality of Communication (Stanford, CA: Stanford University Press, 1998); David Bleich, 'The Materiality of Reading', New Literary History, 37 (2006), 607-29; Bleich, The Materiality of Language: Gender, Politics, and the University (Bloomington, IN: Indiana University Press, 2013); Comparative Textual Media: Transforming the Humanities in the Postprint Era, ed. N. Katherine Hayles and Jessica Pressman (Minneapolis, MN: University of Minnesota Press, 2013); Lori Emerson, Reading Writing Interfaces: From the Digital to the Bookbound (Minneapolis, MN: University of Minnesota Press, 2014); Lisa Gitelman, Paper Knowledge: Toward a Media History of Documents (Durham, NC: Duke University Press, 2014); Lesley Gourlay, 'Posthuman Texts: Nonhuman Actors, Mediators and the Digital University', Social Semiotics, 25 (2015), 484-500; Juliet Fleming, Cultural Graphology: Writing after Derrida (Chicago, IL: University of Chicago Press, 2016); and Matthew G. Kirschenbaum, Track Changes (Cambridge, MA: Harvard University Press, 2016). 
concerns notation's embeddedness in networks of material relations; rather than a binary consideration of representation and musical reality, it considers the mediating role of notation between such networks and potential audiences. The second category describes the process by which the notated sign performs an abstraction from reality, and how this process involves a negotiation of the agency of composers, performers and audiences. The third category addresses the way in which notation plays into or modifies existing relations between musicians and their instruments, reshaping both instrument and musician in the process. By employing these three concepts I hope to show the opportunities of an interdisciplinary approach to a topic that has defined the disciplinary centre of music scholarship for so long.

\section{Mobilization}

One of the most common arguments for a shift away from a work-centred musicology is the idea that notation is incomplete - it 'cannot specify everything' and is 'only a blueprint'. Although such notions highlight the role of the performer's creative contribution, it continues to uphold a representationalist view of notation. It sees notation as a kind of image and evaluates it on the basis of its correspondence to musical reality. The concept of mobilization affords a more performative and constructivist understanding of the nature of the sign. It focuses not on the lack but on the presence of notation; it acknowledges that notation, as Dillon puts it, is not just a writing of music but a writing about music. ${ }^{24}$ Its value lies precisely in meaning or achieving 'something other and more' than what it represents, as Jason Stanyek has recently argued with regard to ethnomusicological transcriptions. ${ }^{25}$

I draw the term 'mobilization' from actor-network theory, where it replaces the idea of the 'correspondence' of scientific models to reality in order to draw attention to the process of translating, filtering and superimposing various measurements, perceptions, discourses, comparisons and calculations in the course of construction of scientific knowledge. It is through such 'layers of transformation' that disparate entities are rendered compatible. ${ }^{26}$ Latour argues that instead of a 'Great Divide' between rational modernity and primitive pre-modernity, there is rather a multiplicity of small steps that make possible the existence of 'immutable mobiles': inscriptions help to stabilize and fix aspects of the material world, but at the same time make them flexible, allowing

${ }^{24}$ Emma Dillon, Medieval Music-Making and the Roman de Fauvel (Cambridge: Cambridge University Press, 2002), 3.

25 Jason Stanyek, 'Forum on Transcription', Twentieth-Century Music, 11 (2014), 101-61 (p. 110).

26 Bruno Latour, Pandora's Hope: Essays on the Reality of Science Studies (Cambridge, MA: Harvard University Press, 1999), 69-79. 
them to be mobilized for the construction of a representation of reality. ${ }^{27}$ This has become an influential approach in science studies. Even mathematics and logic perhaps the only disciplines with a stronger Platonic legacy than musicology - have been reconsidered in terms of their material semiotics and acts of demonstration. ${ }^{28}$ Drawing inspiration from this, we might say that music notation is able to function as a representation because it mobilizes and renders compatible various musicians, instruments, playing techniques, acoustic measurements and music theories ranging from the speculative to the empirical. Scores work not because of their representation of sounding music, but because they construct relations that allow music to sound. ${ }^{29}$

In this context it is important to highlight the continuity between notation and mechanical phonographic sound recording. Scott de Martinville's phonautograph was intended as an automated form of notation (of speech rather than music), and it was realized only later that the mechanical process could be engineered so as to make possible the mechanical production of sound. ${ }^{30}$ That is to say, the relations that allowed music to sound had yet to be constructed for the phonautograph for it to become retrospectively the first form of mechanical sound recording. My definition of notation is intentionally broad, and although in this article I will mostly address symbolic means of representing music, the various means of transmitting and storing - from the grooves of analogue recording to the various formats of the digital era - do meet its conditions. ${ }^{31}$ In other words, the 'musical relations' of my working definition of notations are not

27 Bruno Latour, 'Visualization and Cognition: Thinking with Eyes and Hands', Knowledge and Society, 6 (1986), 1-40.

28 Brian Rotman, Signifying Nothing: The Semiotics of Zero (London: MacMillan, 1987); Math Worlds: Philosophical and Social Studies of Mathematics and Mathematics Education, ed. Sal P. Restivo, Jean Paul Van Bendegem and Roland Fischer (New York: SUNY Press, 1993); Claude Rosental, Weaving SelfEvidence: A Sociology of Logic (Princeton, NJ: Princeton University Press, 2008); Reviel Netz, Ludic Proof: Greek Mathematics and the Alexandrian Aesthetic (Cambridge: Cambridge University Press, 2009); Michael Barany and Donald MacKenzie, 'Chalk: Materials and Concepts in Mathematics Research', Representation in Scientific Practice Revisited, ed. Catelijne Coopmans, Janet Vertesi, Michael Lynch and Steve Woolgar (Cambridge, MA: MIT Press, 2014), 107-29; Christian Greiffenhagen, 'The Materiality of Mathematics: Presenting Mathematics at the Blackboard', British Journal of Sociology, 65 (2014), 502-28.

29 This argument may be compared to Jason Stanyek and Benjamin Piekut's advocacy of a 'rhizophonic' rather than a 'schizophonic' perspective on sound recording, focusing not on a separation of sound from its source (according to which notation might be considered an essentially schizophonic technology), but on the fundamentally fragmented yet proliferative condition of sound reproduction and recording, where sounds and bodies are constantly dislocated, relocated, and co-located in temporary aural configurations'. Jason Stanyek and Benjamin Piekut, 'Deadness: Technologies of the Intermundane', TDR: The Drama Review, 54 (2010), 14-38 (p. 19).

30 J. Mackenzie Pierce, 'Writing at the Speed of Sound: Music Stenography and Recording beyond the Phonograph', 19th-Century Music, 41 (2017-18), 121-50 (pp. 144-5).

31 Jonathan Sterne makes clear that the MP3 is better understood as a format, highlighting its status as a communication technology, rather than as a form of sound recording. Jonathan Sterne, MP3: The Meaning of a Format (Durham, NC: Duke University Press, 2012), 3. 
limited to the musical structures represented by them, which have traditionally been the subject of music analysis. More precisely, the definition and recognition of such musical structures is always embedded in broader conceptions of personal, technological and cultural relations. As stated in the Strathern quotation above, the images that make imagination possible allow us to use some thoughts to think others. ${ }^{32}$

The notion of mobilization thus calls attention to the status of the musical sign as a material object, and simultaneously to its position in a wider material semiotic infrastructure of technologies, discourses and institutions. ${ }^{33}$ Such an understanding of notation has been particularly influential in early-music studies. Following the work of Jerome McGann, Roger Chartier, Gérard Genette and D. F. McKenzie in the field of book history, more and more attention has been given to the ways in which the material production, layout and illustration of manuscripts and early print publications of written music give essential evidence about these notations' meaning and use by contemporary readers. ${ }^{34}$ The display of music in notation may not simply be a recording of sound, but itself a performance of that music. Various early-music scholars have addressed how the visualization and mise-en-page of music in manuscripts served not only to construct knowledge about the music itself, but also to relate this knowledge to ontological or religious beliefs, moral education, political discourse or processes of social distinction. ${ }^{35}$ Such scholarship is increasingly looking to develop

32 One of Strathern's central ideas has been that relations themselves are relationally defined: just as parts are only defined by reference to a supposed whole, so relations between parts are defined in relation to such a broader conception of what constitutes parts and wholes in the first place. Her 'merographic' approach emphasizes that a part of any whole is simultaneously part of another. Marilyn Strathern, After Nature: English Kinship in the Late Twentieth Century (Cambridge: Cambridge University Press, 1992), 72-87.

33 See also Leslie C. Gay, 'Before the Deluge: The Technoculture of Song-Sheet Publishing Viewed from Late Nineteenth-Century Galveston', American Music, 17 (1999), 396-421.

34 Jerome J. McGann, The Textual Condition (Princeton, NJ: Princeton University Press, 1991); Roger Chartier, The Order of Books: Readers, Authors, and Libraries in Europe between the Fourteenth and Eighteenth Centuries, trans. Lydia G. Cochrane (Stanford, CA: Stanford University Press, 1994); Gérard Genette, Paratexts: Thresholds of Interpretation, trans. Jane E. Lewin (Cambridge: Cambridge University Press, 1997); D. F. McKenzie, Bibliography and the Sociology of Texts (Cambridge: Cambridge University Press, 1999).

35 See among others Dillon, Medieval Music-Making and the Roman de Fauvel; Jane Alden, Songs, Scribes, and Society: The History and Reception of the Loire Valley Chansonniers (Oxford: Oxford University Press, 2010); Elizabeth Eva Leach, Guillaume de Machaut: Secretary, Poet, Musician (Leuven: Leuven University Press, 2011); Richard Wistreich, 'Musical Materials and Cultural Spaces', Renaissance Studies, 26 (2012), 1-12; Thomas Schmidt-Beste and Hanna Vorholt, 'Mise-en-page in Medieval and Early Modern Music Sources I: Introduction', Journal of the Alamire Foundation, 6 (2014), 137-8, and 'Mise-en-page in Medieval and Early Modern Music Sources II: Introduction', ibid., 7/1 (2015), 9-10; Vincenzo Borghetti, 'The Listening Gaze: Alamire's Presentation Manuscripts and the Courtly Reader', ibid., 47-66; Manuscripts and Medieval Song, ed. Helen Deeming and Elizabeth Eva Leach (Cambridge: Cambridge University Press, 2015); and Kate van Orden, Materialities: Books, Readers, and the Chanson in Sixteenth-Century Europe (Oxford: Oxford University Press, 2015). 
an understanding of music notation that, unlike the work-concept and its critics, no longer perceives it as antithetical to the social and creative processes that characterize music-making.

From this perspective, the visuality of music notation need not be characterized as a form of 'ocularcentrism' that distracts from musical reality. ${ }^{36}$ The idea of notation as a visual medium and the discourse of absence amplify each other to some extent - after all, the idea of a perfect visual reproduction of sound is a chimera. ${ }^{37}$ However, the visuality of notation need not be understood exclusively in terms of lack and distance. Work on early music notation suggests that this visuality is not a matter of detachment and domination, but of a practical and embodied engagement with a score. ${ }^{38}$ In fact, the very idea of notation as a visualization of sound was partly dependent for its emergence on the materiality of musical writing. ${ }^{39}$ The earliest musical notations drew on techniques of voice modulation in spoken language, and through a general representation of melodic contour served to aid singers, who had their melodies committed to memory. ${ }^{40}$ Rather than precise indications of pitch height, neumes communicated detailed information about phrasing. ${ }^{41}$ However, the visualization of melodic contour then afforded the possibility of indicating precise pitch through a systematization of this visualizing capacity; Rankin speaks of this process in terms of the 'feedback' offered by the externalization of musical thought, 'a cognitive change brought about by the extensive use of musical notation - and the new attitudes thereby developed as to how such a technique might be exploited'. ${ }^{42}$

36 Of course, not all forms of notation are primarily visual: Braille notation for the blind and visually impaired is an obvious example, but there are also notation systems that make use of onomatopoeic syllables such as the bols used in Indian tabla playing, the Japanese shogga syllables used to represent melodies for the nohkan flute and the 'vocables' of early pibroch notations.

37 This is why various scholars in visual studies have criticized the emphasis on vision in modern epistemology. See Jonathan Crary, Techniques of the Observer: On Vision and Modernity in the Nineteenth Century (Cambridge, MA: MIT Press, 1992); Martin Jay, Downcast Eyes: The Denigration of Vision in Twentieth-Century French Thought (Berkeley, CA: University of California Press, 1993); and David Michael Levin, Modernity and the Hegemony of Vision (Berkeley, CA: University of California Press, 1993). It is this discourse that Sterne criticizes as the 'audio-visual litany'.

38 For a general argument to this effect about vision and hearing, see Tim Ingold, 'Stop, Look and Listen! Vision, Hearing and Human Movement', The Perception of the Environment: Essays on Livelihood, Dwelling and Skill (London: Routledge, 2000), 243-87, and W. J. T. Mitchell, 'There Are No Visual Media', Journal of Visual Culture, 4 (2005), 257-66.

39 And as Sybille Krämer has recently argued, such visualization consequently also made it possible for musical structures to emerge as epistemic objects. Krämer, 'Flattening as Cultural Technique: Epistemic and Aesthetic Functions of Inscribed Surfaces', Journal of the American Musicological Society, 70 (2017), 239-45.

40 Leo Treitler, 'The Early History of Music Writing in the West', Journal of the American Musicological Society, 35 (1982), 237-79.

41 Susan Rankin, 'Capturing Sound: The Notation of Language', Cantus scriptus: Technologies of Medieval Song, ed. Emma Dillon and Lynn Ransom (Piscataway, NJ: Gorgias Press, 2012), 10-41.

42 Susan Rankin, 'On the Treatment of Pitch in Early Music Writing', Early Music History, 30 (2011), 105-75 (p. 108). 


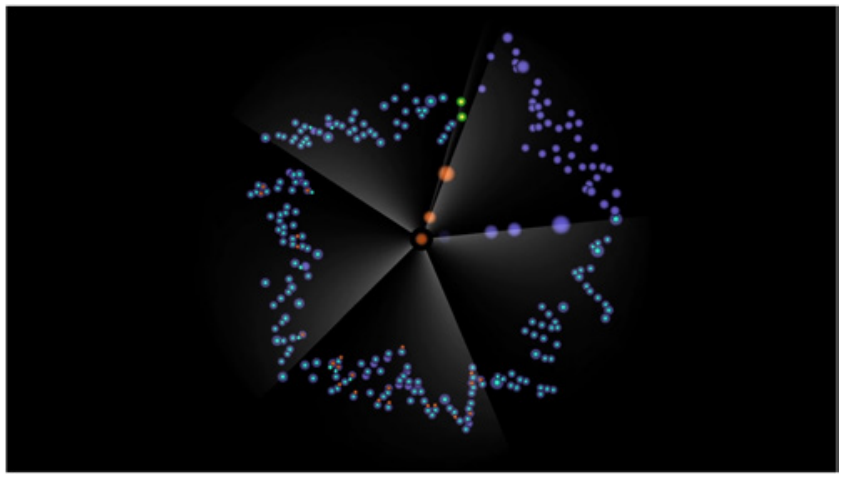

Figure 1. A still from Stephen Malinowski's visualization of Bach's canon at the twelfth from The Art of Fugue (<https://www.youtube.com/watch?v=GhQK4GeqHbA>, accessed 22 December 2017). Reproduced by permission. A full colour reproduction of this figure is available in the online edition of $J R M A$. The coloured dots represent the melodic voices: each transposition has its own colour, and so the changing colours of the dots make clear the canonical structure. The 'spokes' turn counter-clockwise and on them the different entries of voices appear before they follow the canonic melody.

In other words, through its visuality, notation addresses and orientates musicians' musical knowledge and sensory engagement - including their habits of listening. A good example of this function are the Hörpartituren or listening scores created for post-war electronic and acousmatic works, to guide listeners' perception and aid their understanding, as well as to serve as analytical tools. ${ }^{43}$ Contemporary versions of such listening scores are the highly popular YouTube videos of Stephen Malinowski's visualizations of pieces from the classical concert repertory. Initially, these were simplified MIDI-visualizations that highlighted the notes when played; more recently his videos have become more sophisticated, also showing dynamics, sustain and decay, as well as more detailed structural aspects such as imitative counterpoint (see Figure 1). Many respond to these videos by commenting that the colourful lines help them to discover new aspects to these familiar pieces, or even help them learn to play them. Malinowski was asked by Björk to make similar visualizations for her Biophilia album, an album published as an iPad application to form a multimedia, multisensory digital environment in which listeners might experience her music. These visualizations, together with other elements of the application, help to teach the listener/user about

43 Denis Smalley, 'Spectromorphology: Explaining Sound-Shapes', Organised Sound, 2 (1997), 107-26; Manuella Blackburn, 'The Visual Sound-Shapes of Spectromorphology: An Illustrative Guide to Composition', Organised Sound, 16 (2011), 5-13; Volkmar Klien, Thomas Grill and Arthur Flexer, 'On Automated Annotation of Acousmatic Music', Journal of New Music Research, 41 (2012), 153-73. For the application of such practices in therapeutic contexts, see Carl Bergstrøm-Nielsen, 'Graphic Notation as a Tool in Describing and Analyzing Music Therapy Improvisations', Music Therapy, 12 (1993), 40-58, and 'Graphic Notation: The Simple Sketch and Beyond', Nordic Journal of Music Therapy, 19 (2010), 162-77. 
the compositional processes behind the songs on the album, including the invention and use of new instruments and technologies. ${ }^{44}$

But apart from listening habits, the affective presence of music notation can serve to mobilize other forms of knowledge and beliefs. Scholars of medieval and Renaissance music have shown that notation's visual appeal was part of its enticing quality as an object of devotion, and as such an integral part of theological and scholarly discourse. Sam Barrett, discussing various accounts from the ninth to the eleventh century, suggests that neumes were in fact considered representations of the music of a higher realm, and that they thus 'served not only as a pragmatic aide-mémoire, but as a reflexive tool for disciplined knowing' of a higher truth than the earthly practice of singing allowed. ${ }^{45}$ The art historian Beth Williamson has argued that such considerations surrounding music notation were still an important part of European musical thought in the fifteenth century. She discusses various notations and paintings in an argument about the importance of musical notation as part of a material culture of religious devotion that emphasized the 'inner contemplation' of the 'mind's eye'. She suggests that the silence of such visual representations of music might have served as a prompt for spectators to realize the ultimately flawed and corrupted nature of such corporeal objects (at least according to Christian doctrine) and to turn instead to inner contemplation as the real way to higher truths. ${ }^{46}$

Such arguments will be familiar to most early-music scholars, but the way in which they draw attention to notations' embeddedness in broader infrastructures can also shed new light on other repertory, for instance on the emergence of the musical workconcept in the early nineteenth century. James Davies and Deirdre Loughridge describe two separate episodes in the early life of the musical work that serve to illustrate this. Davies discusses the publication in the late 1820s of 'annuals'- commercial gifts serving as 'souvenirs' that contained a variety of popular music of the year gone by (including arias, songs, opera overtures, dances, piano pieces and so on). Made from luxurious materials, using different colours and containing many illustrations and embellishments, they were highly commercial, highly gendered, affective objects of reminiscence about the recent past. As objects of gift-exchange they forged personal and intimate connections between people in an era of romantic nostalgia, and played an important part in the emergence of the concept of musical works as objects for reflection rather than performance. ${ }^{47}$

44 Samantha Blickhan, “'Listening” through Digital Interaction in Björk's Biophilia', Ludomusicology: Approaches to Video Game Music, ed. Michiel Kamp, Tim Summers and Mark Sweeney (Sheffield: Equinox, 2016), 133-51.

45 Sam Barrett, 'Reflections on Music Writing: Coming to Terms with Gain and Loss in Early Music Song', Vom Preis des Fortschritts: Gewinn und Verlust in der Musikgeschichte, ed. Andreas Haug and Dorschel (New York: Universal Edition, 2008), 89-109 (p. 93).

46 Beth Williamson, 'Sensory Experience in Medieval Devotion: Sound and Vision, Invisibility and Silence', Speculum, 88 (2013), 1-43.

47 James Davies, 'Julia's Gift: The Social Life of Scores, c.1830', Journal of the Royal Musical Association, 131 (2006), 287-309. 
Around the same time, the earliest 'facsimiles' appeared. These were not created photographically, but were traced by hand and then copied lithographically. Loughridge has shown how these facsimiles were on the one hand embedded in the construction of intimate personal relations through gift-exchange: these objects were primarily manufactured for the purpose of collection, and collectors revelled in the proximity the facsimiles were deemed to offer to the composer's creative spirit. ${ }^{48} \mathrm{On}$ the other hand, they also played a role in emerging scholarly discourse around music. The appreciation of composers' handwriting was amplified by the emergence of the pseudo-science of physiognomy and its suggestion that one could deduce someone's true character from their handwriting. Such examples tell a rather more concrete and tangible story about the rise of the work-concept than general discussions of the influence of Romantic idealism.

Of course, the mobilization of the sign does not imply that the infrastructures involved in it are automatically mobilized by the sign. The actor-network theorist Madeleine Akrich speaks of describing the social role of technologies in terms of 'the world inscribed in the object and the world described by its displacement. ${ }^{49}$ Various notation systems have been proposed in attempts to improve staff notation - for instance by composers such as Busoni and Schoenberg, who sought more appropriate ways to represent their music, or by idealist educators such as Cornelis Pot, who aimed to develop a form of notation more easily understandable by amateurs. ${ }^{50}$ However, despite the universalizing gestures of such forms of notation (recognizable most clearly in the Esperanto of Pot's 'klavarskribo'), they have suffered from a lack of readily available infrastructure to sustain their use beyond a direct circle of influence. As Mackenzie Pierce argues with respect to music stenography, such technologies are all the more interesting because they can show both the assumptions and fantasies that surrounded musical writing and their dialectical relation to the practical considerations that ultimately led to the failure of the technologies themselves. ${ }^{51}$ To use the language of actor-network theory, modern staff notation has many 'allies', including music education curricula, textbooks, computer programmes, publishing companies and so on, that work to keep it the default mode of notation. The dynamics by which real and projected audiences are negotiated through the writing and use of notation might also uncover how the universality or hegemony of Western music notation is not a

48 Deirdre Loughridge, 'Making, Collecting and Reading Music Facsimiles before Photography', Journal of the Royal Musical Association, 141 (2016), 27-59.

49 Madeleine Akrich, 'The De-Scription of Technical Objects', Shaping Technology / Building Society, ed. Bijker and Law, 205-24 (p. 209).

50 Arnold Schoenberg, 'A New Twelve-Tone Notation', Style and Idea: Selected Writings of Arnold Schoenberg, ed. Leonard Stein (Berkeley, CA: University of California Press, 1975), 354-62; Erinn Knyt, 'Between Composition and Transcription: Ferruccio Busoni and Music Notation', TwentiethCentury Music, 11 (2014), 37-61.

51 Pierce, 'Writing at the Speed of Sound'. 
given, but is contingent on processes of transformation, mobilization, dissemination and stabilization.

It is through this process of negotiation that the dynamics between projected and real audiences are enacted. Cook gives an example of this when he discusses the British genre of Hindostannie airs, a faux-Indian genre often associated with nineteenth-century musical orientalism. Cook argues that the 'first generation' of such airs, transcribed in India in the eighteenth century, are not (merely) instances of orientalism but suggest a genuine interest in and understanding of one aspect of Indian musical culture; part of his argument is the 'deformation' of common-practice notational conventions found in these transcriptions. However, as he suggests, whereas for the original transcribers these notations 'would have mobilized and reconfigured remembered experiences, $[\ldots]$ the musicians back in London had no such memories to be mobilized'. ${ }^{2}$ These musicians in London saw transcriptions with what just seemed to them like mistakes. One of them commented: 'I have suspected them to have been committed to paper by some unskilful hand, so as to have deviated from the native Melody. ${ }^{53}$ Later airs in this genre had 'corrected' these deformations so as to correspond better to the British idea of Indian music, but these had little to do any more with the Indian singing styles they had originally imitated.

A contemporary example of how such dynamics can be negotiated is Beck's 2012 Song Reader album, which did not come in the form of a recording but only as sheet music. The promotional material surrounding the album expressed nostalgia for the forms of informal amateur music-making prevalent in the nineteenth century. As Kate Maxwell argues, apart from the fact that it is another example of the affective visual presence of notation, the album may be seen as a performance of identity in its own right. ${ }^{54}$ Although the book contains no images of the artist, it serves to solidify Beck's status as an authentic, 'alternative' musician, one responding to the ubiquity of digital technology in contemporary popular music. ${ }^{55} \mathrm{In}$ fact, the music video for Jack White's recording of one of these songs puts centre stage an animated version of the sheet music, rather than either of the two musicians. Of course, the nostalgic gesture is dependent on the infrastructure of a modern music industry against which to position itself, and White's music video also uses digital animation technologies to underscore the authenticity of this pre-digital music technology. Particularly telling of this interdependence of nostalgic authenticity and the modern industrial infrastructure in which it is embedded is the fact that an album with recorded versions of these songs

52 Nicholas Cook, 'Anatomy of the Encounter: Intercultural Analysis as Relational Musicology', Musicological Reflections: Essays in Honour of Derek B. Scott, ed. Stan Hawkins (New York: Routledge, 2012), 193-208 (p. 206).

53 Ibid., 205.

54 Kate Maxwell, 'Beck's Song Reader: An Unbound Music Book', Mémoires du livre / Studies in Book Culture, 8 (2016), <https://id.erudit.org/iderudit/1038035ar> (accessed 24 April 2014).

55 On the interdependence of technology and authenticity, see Simon Frith, 'Art Versus Technology: The Strange Case of Popular Music', Media, Culture and Society, 8 (1986), 263-79. 
by various artists was released in 2014, despite earlier statements that the album would be released only in written form.

\section{Entextualization}

The category of mobilization calls attention to the indexical, material-semiotic networks in which notation is embedded. However, as a sign it performs an abstraction from material reality, which has consequences both for musical ontology and for conceptions of creative agency. As an example, let me contrast two commentaries on musical writing by Theodor Adorno and Robert Schumann. Adorno, despite his widely perceived distaste for both audio recording and opera, still praised the long-playing record in his later work because it allowed for the 'optimal presentation of music', an 'objectification, that is, a concentration on music as the true object of opera', doing away with all the visual and theatrical elements, an experience that he compared to reading and its affordance of 'the immersion in a text'. ${ }^{56}$ To Adorno, the grooves of the phonograph record offered a glimpse of a 'true language' of music, a writing superior to the imprecision of staff notation, albeit at the expense of musical immediacy. ${ }^{57}$ If Adorno's ideal of writing praised the abstraction that notation and sound recording afford, Schumann described his reading experience of Chopin's variations on 'Là ci darem la mano' for piano and orchestra in much more affective and embodied terms, which bring to mind Davies's and Loughridge's arguments on the affective presence of scores at this time, and which emphasize particularly the visual and theatrical elements that Adorno was so happy to get rid of:

I leafed about absentmindedly among the pages; this veiled silent enjoyment of music has something magical about it. Furthermore, as it seems to me, every composer has his own special way of arranging notes for the eye: Beethoven looks different on paper from Mozart, very much as Jean Paul's prose looks different from Goethe's. In this case, however, it was as though unfamiliar eyes were everywhere gazing out at me strangely flower-eyes, basilisk-eyes, peacock-eyes, maiden-eyes; here and there things grew clearerI thought I saw Mozart's 'Là ci darem la mano' woven about with a hundred harmonies; Leporello seemed to be actually winking at me, and Don Giovanni flew past me in a white cloak. ${ }^{58}$

56 Theodor W. Adorno, 'Opera and the Long-Playing Record', trans. Thomas Y. Levin, October, 55 (1990), 62-6 (p. 64).

57 Theodor W. Adorno, 'The Form of the Phonograph Record', trans. Thomas Y. Levin, October, 55 (1990), 56-61; Thomas Y. Levin, 'For the Record: Adorno on Music in the Age of its Technological Reproducibility', October, 55 (1990), 23-47.

58 Robert Schumann, 'An Opus Two', Source Readings in Music History: From Classical Antiquity through the Romantic Era, ed. Oliver Strunk (New York: W. W. Norton, 1950), 829-31 (p. 830). 
Clearly, Adorno and Schumann find very different things in their texts. I employ the concept of entextualization to refer to the social processes by which people determine what is 'part of' or 'inside' a musical text.

Entextualization is a concept taken from linguistic anthropology, where it was introduced in 1990 by Richard Bauman and Charles Briggs as 'the process of rendering discourse extractable, of making a stretch of linguistic production into a unit - a text - that can be lifted out of its interactional setting. ${ }^{59}$ By calling attention to the work needed to establish and maintain a text's coherence and unity, Bauman and Briggs intended to avoid hard distinctions between text and performance, literacy and orality. It is important to realize that linguistic anthropology is mostly concerned with speech, and so entextualization is not a matter of writing or otherwise recording speech; only recently have linguistic anthropologists started to address the materiality of entextualization. ${ }^{60}$ Entextualization describes the process of demarcating abstract objects such as stories, myths, songs and saying in the flow of spoken language, and in doing so it reconfigures interpersonal relations and allows speakers to speak in names other than their own (such as deities or forefathers) and to address their listeners not just as individuals but as members of a particular community. Karin Barber employs the concept of entextualization to analyse how texts (which in her book, significantly, are often songs) are used to assume a role of authority, reflect on one's own or a community's behaviour, assume cultural identities through genre conventions, call upon audience members as social actors and so on. Such examples show, as she argues, that 'textual traditions can be seen as a community's ethnography of itself', not just because of the stories they tell but because of the negotiations of social relations involved in making those stories. ${ }^{61}$ She writes: 'What we may need is not a binary division between cultures that build monuments and those that don't, but a comparative view of what kind of fixing they do, and what models and idioms they use to describe it. ${ }^{\prime} 2$

Entextualization is a process that is at once ontological and ethical. To return to the definition of notation given in the introduction, this has important consequences for how we understand 'musical' relations. A central element (perhaps the central element) of the work-concept lies in the way in which it identifies writing with text, and sees the composer as the primary creative agent of that text. Considering the centrality of music

59 Richard Bauman and Charles L. Briggs, 'Poetics and Performance as Critical Perspectives on Language and Social Life', Annual Review of Anthropology, 19 (1990), 59-88 (p. 73).

60 Patrick Eisenlohr, 'Materialities of Entextualization: The Domestication of Sound Reproduction in Mauritian Muslim Devotional Practices', Journal of Linguistic Anthropology, 20 (2010), 314-33; Ilana Gershon and Paul Manning, 'Language and Media', The Cambridge Handbook of Linguistic Anthropology, ed. N. J. Enfield, Paul Kockelman and Jack Sidnell (Cambridge: Cambridge University Press, 2014), 559-76.

${ }^{61}$ Karin Barber, The Anthropology of Texts, Persons and Publics (Cambridge: Cambridge University Press, 2007), 3.

62 Ibid., 24-5. 
notation to the work-concept and its associated idealist ontology of music, we may find that different notation cultures articulate different ontologies of music. ${ }^{63} \mathrm{~A}$ drastic consequence of the notion of entextualization is that it decouples writing and text. Because of this, notation becomes a way not to define a text but rather to negotiate the relation between text and performance - which is what it means to think of notation as an interface. Musicians in performance relate to each other not just as the persons they are, but as musicians and in correspondence with the music. This may be in order to mediate vicariously the composer's intentions for the work, or it may just be that they relate to the emerging musical situation in an improvisation. Different musical ontologies allow musicians to position themselves differently as agents in relation to the various processes of social interaction that characterize performance. ${ }^{64}$

Musicians who argue in rehearsal over what the composer of a piece would have wanted or intended are engaging in such negotiations. Rather than viewing them as dupes of a work-centred ideology, the concept of entextualization suggests that we might describe such processes in far more diverse ways than simply the subjugation to a composer's authority, asking how authority and agency are invoked, delegated or undermined, and how a performer's musical understanding is developed in the process. Amanda Bayley cites the cellist David Waterman, who comments on scores featuring a large number of performance markings:

On the one hand, the markings are too dense, which can lead to nuances becoming fussy and exaggerated or can induce a stiff adherence to instructions, without the understanding that would make the markings organically part of the music. On the other hand, if these composers were really hoping to define a performance, then even their copious markings are quite insufficient. ${ }^{65}$

63 Philip Bohlman, 'Ontologies of Music', Rethinking Music, ed. Nicholas Cook and Mark Everist (Oxford: Oxford University Press, 1999), 17-34. Proponents of a so-called 'ontological turn' in anthropology have turned to investigate cultures and societies not in terms of their 'world-views' but rather as practices of world-building. See Annemarie Mol, 'Ontological Politics: A Word and Some Questions', Sociological Review, 47/S1 (1999), 74-89; Thinking Through Things: Theorising Artefacts Ethnographically, ed. Amiria Henare, Martin Holbraad and Sari Wastell (London: Routledge, 2007); Morten Axel Pedersen, 'Common Nonsense: A Review of Certain Recent Reviews of the "Ontological Turn"', Anthropology of This Century, 5 (2012), <http://aotcpress.com/articles/common_nonsense> (accessed 8 March 2019); Martin Paleček and Mark Risjord, 'Relativism and the Ontological Turn within Anthropology', Philosophy of the Social Sciences, 43 (2013), 3-23; and Martin Holbraad and Morten Axel Pedersen, The Ontological Turn: An Anthropological Exposition (Cambridge: Cambridge University Press, 2017).

64 Webb Keane notes, in a critical commentary on the ontological turn in anthropology, that ontological matters often revolve around ethical questions concerning humans accountability towards each other, to the world, or to spirits or deities. This does not invalidate a turn to ontology, but it does imply that such concerns cannot be separated from considerations of authorship and audience, and from the delegation of agency. Keane, 'Ontologies, Anthropologists, and Ethical Life', HAU: Journal of Ethnographic Theory, 3 (2013), 186-91.

65 Amanda Bayley, 'Ethnographic Research into Contemporary String Quartet Rehearsal', Ethnomusicology Forum, 20 (2011), 385-411 (p. 389). 
The comment is particularly interesting because it suggests that the process of entextualization, determining what is 'part of the music' and what is not, is a crucial feature of learning a piece, and the 'incompleteness' of notation thus should not be understood negatively, but as an opportunity affording creative engagement by the performer.

Indeterminate music has made this engagement into one of its main characteristics by asking the performer to become a 'co-creator' through the realization of indeterminate scores. On the one hand, this seems only to perpetuate the identification of writing with text and of musical invention with writing, as this co-creatorship is achieved only by ceding some of the creative 'writing work' to the performer. On the other hand, by putting these categories of authorship and performance into question, such pieces can be seen as 'testing' our conceptions of the roles of composer and performer. James Pritchett, for instance, argues that David Tudor's realization of John Cage's Variations II may be seen as Tudor's own composition rather than as a realization of Cage's piece, because unlike Tudor's previous meticulously measured and fully notated realizations of such pieces, this one is itself another indeterminate piece specifying actions to be performed rather than sounds. ${ }^{66}$ The argument hinges on a definition of 'composer' that would in any other context be very peculiar, as we would normally consider a composer to be that person who does specify sounds to be performed, rather than actions. Experimental music has more generally questioned in whose 'name' performers are making music, giving rise to a much more diverse landscape than the 'desubjectivization' that we have come to associate with the work of Cage. In Emmett Williams's Fluxus piece Voice Piece for La Monte Young ('ask if La Monte Young is in the audience, then exit'), it is unclear who is the performing agent - the person asking, or La Monte Young (not) answering, or perhaps an audience member, mistaking it for a real question, saying that he just left. Such a delegation of the role of performer to a possibly unaware audience was a frequent characteristic of Fluxus pieces.

These examples still mostly trade in what I called in the previous section the 'discourse of absence', as it continues to locate the agency of the performer in what is not written by the composer. The decoupling of writing and text, however, suggests that there are other possibilities. A particularly intricate example is documented by Eric Clarke, Mark Doffman and Liza Lim in their study of the preparation by the ensemble MusikFabrik and the pianist Uri Caine of Lim's Tongue of the Invisible. ${ }^{67}$ Lim's composition features various freely improvised as well as indeterminate passages, and it was her intention not to dominate the rehearsal process but to let creative decisions emerge through the interactions of the rehearsing musicians. However, this open-ended way of working led to some frustrations in the group, as some

66 James Pritchett, 'David Tudor as Composer/Performer in Cage's "Variations II", Leonardo Music Journal, 14 (2004), 11-16.

67 Eric Clarke, Mark Doffman and Liza Lim, 'Distributed Creativity and Ecological Dynamics: A Case Study of Liza Lim's "Tongue of the Invisible", Music and Letters, 94 (2013), 628-63. 
musicians wanted to have more certainty about what was expected of them, while others appreciated the interpretative freedom. Clarke, Doffman and Lim describe how at one point, despite earlier agreements that it would be better to leave open how a certain passage would be played, Lim and the conductor André de Ridder did give the musicians instructions after some less successful improvisations. This act of fixing turns out to be an important moment in the creative process, not because the musicians then stick to this agreement, but because they feel that establishing a certain direction in the improvisation is now 'allowed', hence liberating them from a more reticent approach because the direction is supposed to be 'emergent'. The possibility of fixity and determination thus paradoxically gives an impetus to the group to improvise more freely. ${ }^{68}$

This indicates that notation need not be considered in terms of what Christopher Williams calls the 'prescription-preservation' paradigm that is so prevalent in music scholarship. ${ }^{69}$ Williams calls attention to the largely neglected repertory of notations for improvising musicians (which has a complex and variable relation to the CageTudor axis of experimental composition) and their 'ability not only to transmit, but to co-produce meaning in interaction with the performer' ${ }^{70}$ Discourses on free improvisation usually emphasize the autonomy of the musician in opposition to the hierarchical relations supposedly inherent in musical practices that use notation, but such arguments seem to rest precisely on the 'prescription-preservation' paradigm diagnosed by Williams. In my ethnographic work on the improvising collective the Instant Composers Pool, the saxophonist Tobias Delius indicated to me that the written materials used in their improvised performances have a rather different function from that which such a paradigm would suggest: 'The purpose of the written material is to disrupt a "nice flow" of improvisation. It can create more anarchy than improvisation sometimes. ${ }^{71}$ There are plenty of other improvisatory musical practices in which written notation is integral to a particular form of improvisation. Systems of conducted improvisation, such as the ones developed by Butch Morris or Walter Thompson featuring hand signs and gestures to communicate musical ideas to a group of performers, are examples of such practices. Another example in which a particular form of notation makes possible a specific practice of improvisation is live coding, in which practitioners improvise writing computer code for digital audio production, keeping in mind not just the mechanics of the digital system but also the algorithms they have already written since it determines how new code will be translated into

68 Clarke, Doffman and Lim, 'Distributed Creativity and Ecological Dynamics', 647-54.

69 Christopher Williams, 'Tactile Paths on and through Notation for Improvisers' (University of Leiden, 2017), <http://www.tactilepaths.net> (accessed 8 March 2019). The classic formulation of this paradigm is Charles Seeger, 'Prescriptive and Descriptive Music-Writing', Musical Quarterly, 44 (1958), 184-95.

70 Williams, 'Tactile Paths', chapter Omega.

71 Floris Schuiling, 'The Instant Composers Pool: Music Notation and the Mediation of Improvising Agency', Cadernos de arte e antropologia, 5 (2016), 39-58 (p. 50). 
audio. Nicolas Collins, for this reason, compares live coding to reading a Choose Your Own Adventure book (and rewriting some of its chapters) or playing a game in which the rules are generated in the course of play. ${ }^{72}$

In all these practices, improvisation and notation are entwined rather than opposed. Barber suggests that 'people's ceaseless innovative and re-creative activity is often directed precisely towards making a mark that transcends space and time. Improvisation and the art of making things stick cannot be separated: we find them everywhere fused and intertwined. ${ }^{73}$ Leo Treitler's work on the earliest musical notations argued that it is essential to recognize the improvisatory musical context in which surviving sources were used, but at the same time that modern understandings of improvisation are not applicable to this context, since they assume the notion of musical writing as determining a 'text', which was simply not the function of writing music in this period. ${ }^{74}$ Even when staff notation was firmly in place, the fact that most music was still disseminated in parts meant that notations did not visually 'embody' a work in the way that a score would. Kate van Orden and Richard Wistreich have each described how performers of popular chansons in the sixteenth century would sight-read their parts, negotiating entries and contrapuntal relations, being surprised by imitations in other voices or other unexpected twists in the music, and thus playfully negotiating the interrelations between their different melodies - in a manner that is improvisatory precisely because of the way the music has been written down and distributed between different parts. Wistreich writes that 'what were essentially accidents of the pragmatics of partbook mechanics that professionals simply had to negotiate, could, however, become for amateur readers delightfully diverting challenges' (see Figure 2) ${ }^{75}$

This brings me to the material means of communication that play a role in the entextualization of music. To say that notation automatically specifies a text would be overly deterministic, yet, as Wistreich noted, the 'essentially accidental' pragmatics of partbook mechanics did give rise to the playful performance practices of sixteenthcentury chansons. In fact, the very possibility of creating a new 'text' through writing similarly came about through such accidental aspects. The adoption of staff notation gradually emerged from the increased use of previously non-essential aspects of manuscripts (from a musical perspective), namely ruling lines, to function as a cipher for pitch height. ${ }^{76}$ Whereas with neumatic notation the 'texts' had already existed

72 Nick Collins, 'Live Coding of Consequence', Leonardo, 44 (2011), 207-11.

73 Karin Barber, 'Improvisation and the Art of Making Things Stick', Creativity and Cultural Improvisation, ed. Elizabeth Hallam and Tim Ingold (Oxford: Berg, 2007), 25-41 (p. 25).

74 Treitler, With Voice and Pen, 39-67.

75 Iain Fenlon, Franco Piperno, Kate van Orden, Amedeo Quondam, Paolo Cecchi and Richard Wistreich, 'Imparare, leggere, comprare musica nell'Europa del Cinquecento', Il saggiatore musicale, 18 (2011), 173-244 (pp. 240-1). See also Wistreich, 'Musical Materials and Cultural Spaces', and van Orden, Materialities, 6.

76 John Haines, 'The Origins of the Musical Staff', Musical Quarterly, 91 (2008), 327-78. 


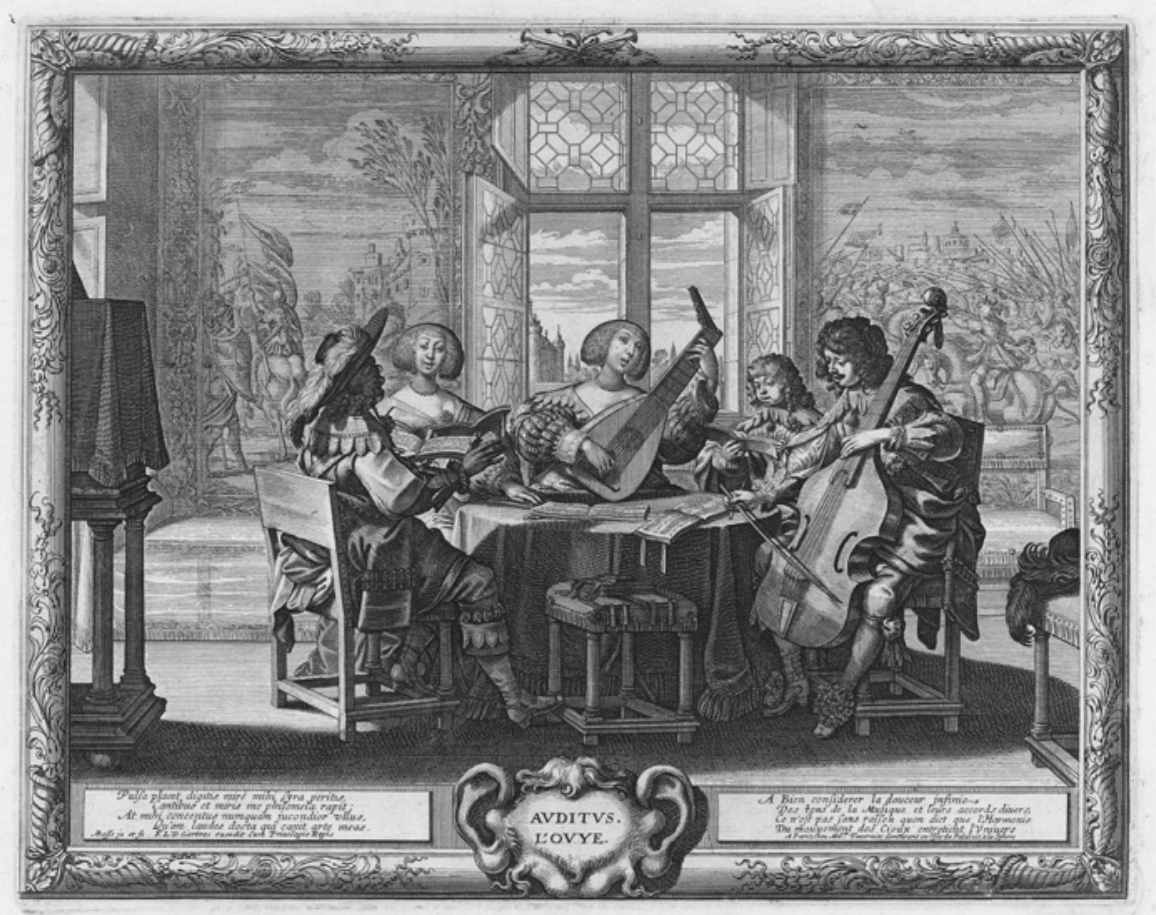

Figure 2. Abraham Bosse, Auditus or L'ouye (Hearing). Amsterdam, Rijksmuseum. Van Orden points out the close coordination and conviviality depicted here by comparing it to a 'card game in which players constantly judge each other's hands, for no one can see how all the parts fit together from his or her own part book'. Kate van Orden, Materialities: Books, Readers, and the Chanson in Sixteenth-Century Europe (Oxford: Oxford University Press, 2015), 6.

before they were written down, the adoption of this cipher allowed for people to invent new music through writing.

The material means of entextualization also have ethical consequences, as is particularly evident in copyright law, which revolves to a large extent around the question of the material form in which a musical idea is recorded. ${ }^{77}$ The jurisprudence on musical copyright is a particularly salient chronicle of how societies have conceptualized authorship in relation to different forms of material entextualization. Since the emergence of musical copyright, musicians have of course not stopped writing down previously existing musical texts. The history of jazz lead-sheets revolves for a significant part around the attempts to write down and stabilize an aurally shared and disseminated repertory of popular songs and original compositions, which led to many disputes over the copyright infringements constituted by such fake books. More recently, there has

77 Lisa Gitelman, 'Media, Materiality, and the Measure of the Digital, or The Case of Sheet Music and the Problem of Piano Rolls', Memory Bytes: History, Technology, and Digital Culture, ed. Lauren Rabinovitz (Durham, NC: Duke University Press, 2004), 199-217. 
been a similar development with regard to guitar tablature. With the rise of the internet, many guitarists shared transcriptions of chord schemes, guitar riffs and solos on a variety of dedicated websites. Just like the fake books of a few decades earlier, many of these transcriptions contained mistakes, and there has been a recent attempt, using phone and tablet applications, to get users to pay for legally transcribed and accurate alternatives. In these examples, the process of material entextualization can almost be described as constituting a 'genre' of straight-ahead jazz or guitar-based popular music. Cook describes a similar situation in connection with the various variations, embellishments and derivations of Corelli's Violin Sonatas op. 5, arguing that it 'might almost be described as constituting a musical genre rather than just being a set of twelve compositions.$^{78}$ A significant difference, of course, is that the issue of legality was not raised in the eighteenth century, since musical copyright had not yet been established. As Roger Moseley has argued, we might fruitfully consider much eighteenth-century music in terms of the entextualization of musical forms that emerged in the interplay between aurally transmitted frameworks (the 'schemata' described by scholars such as Robert Gjerdingen and Robert Levin) and their improvisatory realizations. ${ }^{79}$ Moseley suggests that the notion of entextualization in the context of the written 'remains' of the highly improvisatory musical practices of eighteenth-century Europe implies, among other things, that notation might be better thought of as an archaeological rather than a historical source - meaning that it functioned as a form of material musical culture rather than as a literary description of that musical culture.

\section{Remediation}

The concept of mobilization emphasizes that the musical sign needs to be part of a broader social and technological infrastructure for it to work. The notion of entextualization suggests that notation does not define a text but is rather a means of negotiating between text and performance; a process which is simultaneously ontological and ethical, because it concerns how we distribute responsibility and agency. The concept of remediation combines these two points to describe how notation mobilizes various forms of social and technological mediation in the process of negotiating between text and performance, and how it configures the agency of musicians in the process.

To give an example: the score for the Fluxus artist Tomas Schmit's Typewriter Poem (see Figure 3) shows a diagrammatic representation of a typewriter keyboard, with numbers on the keys to indicate the sequence in which they should be struck. On performance of this piece, the (possible) typed end result reads: 'if your typewriter is

78 Cook, Beyond the Score, 228.

79 Roger Moseley, 'Entextualization and the Improvised Past', Music Theory Online, 19 (2013), <http:// mtosmt.org/issues/mto.13.19.2/mto.13.19.2.moseley.html> (accessed 8 March 2019). 


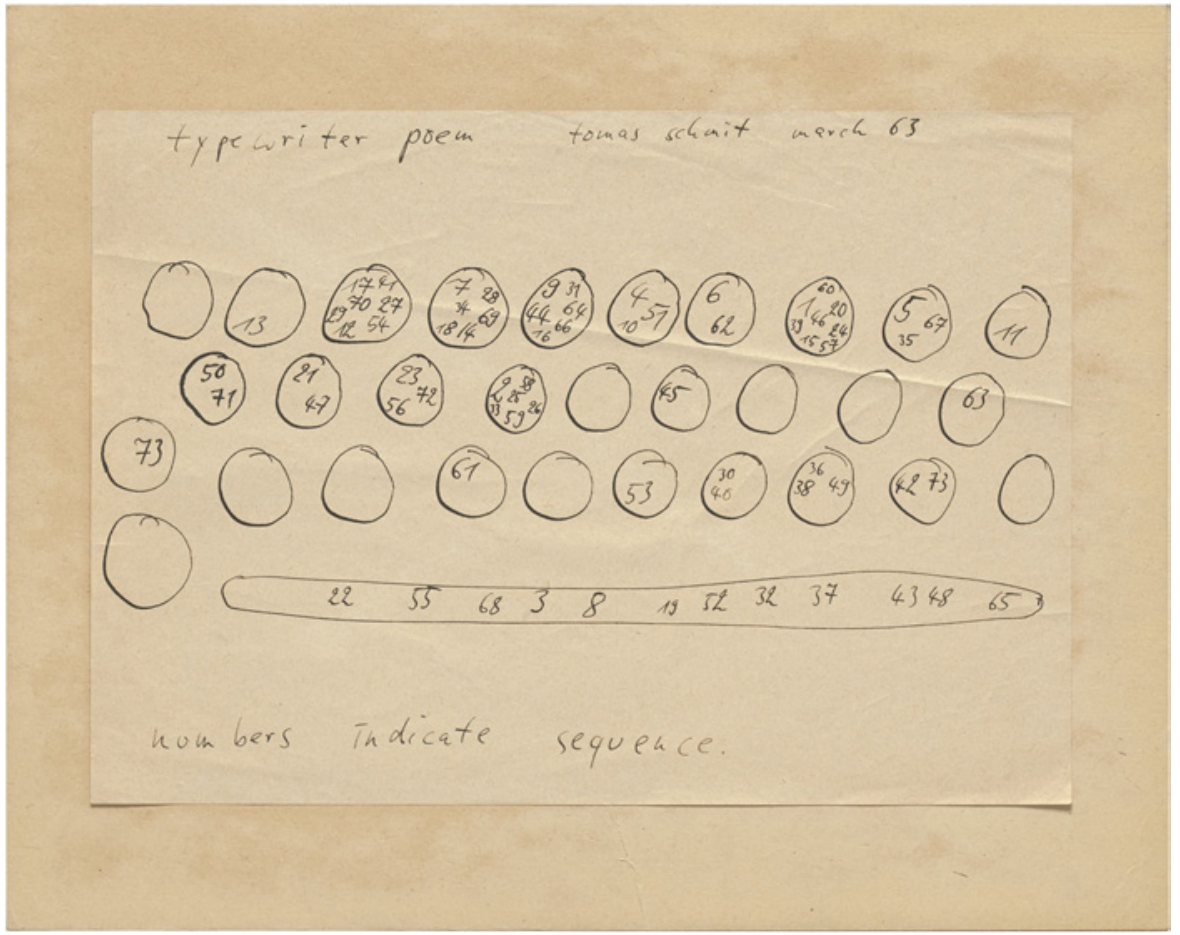

Figure 3. Tomas Schmit, Typewriter Poem, 1963. New York, Museum of Modern Art (<https://www. moma.org/collection/works/136670>).

different from mine, this may be difficult to read.' ${ }^{80}$ Schmit's piece highlights that the way in which we come to relate sign and signified is not purely a mental operation, but depends on material and technological processes. A consequence of the attention to materiality in book history that I mentioned in the section on mobilization has been a reconsideration of the practice of reading itself. As Chartier has suggested, 'Reading is not uniquely an abstract operation of the intellect: it brings the body into play, it is inscribed in a space and a relationship with oneself and with others. ${ }^{81}$ With the rise of electronic literature and the possibility of making digital editions, such ideas have also had a strong impact on the study of contemporary literature. ${ }^{82}$ In contrast to earlier assumptions about literature as 'not having a body, only a speaking mind', ${ }^{83}$ various

80 In the Spirit of Fluxus, ed. Janet Jenkins (Minneapolis, MN: Walker Art Center, 1993), 159.

81 Chartier, The Order of Books, 8.

82 N. Katherine Hayles, Writing Machines (Cambridge, MA: MIT Press, 2002); Comparative Textual Media, ed. Hayles and Pressman.

83 Hayles, Writing Machines, 32. 
scholars have started to address the 'body language' of texts. ${ }^{84}$ As Laurence Dreyfus has pointed out, the concept of 'interpretation', though frequently used to emphasize the creative efforts of the performer, is a very recent concept as applied to musical performance, emerging with the advent of late Romanticism in the second half of the nineteenth century. Dreyfus argues that the term turns the score into a vessel for the composer's genius, with hidden mysteries to be discovered and revealed. ${ }^{85}$ In fact, Mary Hunter argues that this discourse emerged even earlier in the nineteenth century, from an ethical ideal of spiritual and bodily transformation, with the performer merging with the genius of the composer through a dialectic of subject and object. ${ }^{86}$

Playing music from notation is a prime example of a form of 'reading' that is only very partially described in terms of corresponding symbols with meanings. Such correspondence is in fact dependent on a reader's embodied and practical skills. Kawori Iguchi, describing her experience of learning to play Japanese nohkan music, writes:

When my (more experienced) fellow students claimed to 'sight-read' a line of unlearned shöga and work out its fingering, it appeared that it was not because they had acquired a firmer grasp of the logic on which the correspondence between the shogga characters and yubitsuke symbols was made, but because they had accumulated enough experience to recognise the resemblance of the new melody to previously learned pieces and lines and were able to deduce how the melody should go by referring to its title, the overall structure of the piece and the position of a line within it. ${ }^{87}$

Such a description suggests that the relation between sign and sound is dependent on its embeddedness in a broader practical context of musical skills and knowledge. Emily Payne and I pursue a similar point in an article in which we discuss performers' score annotation to uncover the combination of visual, tactile and motoric knowledge involved in negotiating the space between notated music, instrumental practice and resulting sound. ${ }^{88}$ We describe score annotations as a means of 'weaving' together the descriptive and prescriptive functions of notation. One of our examples is of a performer using arrows to indicate unfamiliar fingering on a basset clarinet; the performer calls such arrows 'sat nav stuff' or a 'map' to navigate the 'geography' of the instrument's keywork. We argue that making such markings is not intended

84 Tore Rye Andersen, “'Black Box" in Flux: Locating the Literary Work between Media', Northern Lights: Film and Media Studies Yearbook, 13 (2015), 121-36 (p. 122).

85 Laurence Dreyfus, 'Beyond the Interpretation of Music', Dutch Journal of Music Theory, 12 (2007), 253-72.

86 Mary Hunter, "To Play as if from the Soul of the Composer": The Idea of the Performer in Early Romantic Aesthetics', Journal of the American Musicological Society, 58 (2005), 357-98.

87 Kawori Iguchi, 'Reading Music / Playing Music: The Musical Notations of the Kyoto Gion Festival and the Noh Flute', Ethnomusicology Forum, 17 (2008), 249-68. See also the work of Howard Becker and Robert Faulkner on learning repertoire in jazz: Robert R. Faulkner and Howard S. Becker, 'Do You Know...?' The Jazz Repertoire in Action (Chicago, IL: University of Chicago Press, 2009).

88 Emily Payne and Floris Schuiling, 'The Textility of Marking: Performers' Annotations as Indicators of the Creative Process in Performance', Music and Letters, 98 (2017), 438-64. 
to 'represent' any previously existing musical information, but rather to negotiate performers' understanding of their instruments, their relation to fellow musicians and their sense of direction during the performance.

I employ the term 'remediation' to address how notation constructs its relations to such other forms of social and technological mediation. The term was coined by Jay David Bolter and Richard Grusin, who use the term to characterize how all media are partly defined by their relation to other media. ${ }^{89}$ Whereas Bolter and Grusin are primarily interested in the way in which technologies highlight or negate their own mediality, I am more interested in how notation plays into the habits and conventions of musicians to establish a relation between sign and object. Lisa Gitelman emphasizes that remediation is a way of playing into the 'protocols' that surround media and by virtue of which they have acquired a functionality in everyday life. ${ }^{90}$ By negotiating such protocols, media anticipate particular users as well as contexts of use. Gitelman's argument is formulated in opposition to overly deterministic accounts of media history that portray media as autonomous agents, thereby neglecting the social and political interactions that have made them appear as such in the first place. We may connect this argument to the critique of the work-concept in music scholarship and indeed to theories of human creativity more generally: a central element of Cook's argument for a performative turn in musicology has been his critique of the 'paradigm of reproduction' in thinking about performance - the idea that performance is a matter of 'bringing out something that is already there in the score, composed into it and just waiting to be released by the performer'. ${ }^{91}$ This paradigm of reproduction is a strong version of what Tim Ingold has called 'hylomorphism'. It implies a conception of creative work that defines it as the application of a pre-existing model or blueprint to shapeless matter, and it perceives the mind as the primary agent of such creation of form. ${ }^{92}$ Instead, Ingold argues, creating form is a matter of working with materials rather than against them; Schmit's poem similarly points out that there is nothing 'already there in the score', but that the score is realized by making use of the affordances of technological media.

The 'virtual' musical relations in my definition of notation should thus not be understood in terms of visual simulation made possible by means of computing. The virtual is a concept with a much longer philosophical history. Charles Sanders Peirce defines the virtual in this more traditional philosophical sense as follows:

A virtual $\mathrm{X}$ (where $\mathrm{X}$ is a common noun) is something, not an $\mathrm{X}$, which has the efficiency (virtus) of an X. This is the proper meaning of the word: but it has been seriously confounded

89 Jay David Bolter and Richard Grusin, Remediation: Understanding New Media (Cambridge, MA: MIT Press, 1999).

90 Lisa Gitelman, Always Already New: Media, History, and the Data of Culture (Cambridge, MA: MIT Press, 2006), 7-8.

91 Cook, 'Making Music Together', 338; Cook, Beyond the Score.

92 Tim Ingold, 'The Textility of Making', Cambridge Journal of Economics, 34 (2010), 91-102. 
with 'potential', which is almost its contrary. For the potential $\mathrm{X}$ is of the nature of $\mathrm{X}$, but is without actual efficiency. ${ }^{93}$

Similarly, but more concisely, Gilles Deleuze writes that, 'The virtual is not actual, but as such possesses a reality. ${ }^{94}$ Just as Peirce distinguishes the virtual from the potential, Deleuze distinguishes it from the possible, which may be actual but is not real. In both definitions, the virtual serves to signify a thoroughly anti-Platonic understanding of the relation between score and sound, as it does not necessarily depend on any similarity or semblance to the music 'in' the score. Rather, Peirce's emphasis on the efficiency of the virtual seems to align it with his concept of the index, a sign that refers to its signified by virtue of causation or contiguity. At the same time, his emphasis that the virtual has the effect of something which it is not suggests that this indexicality is simultaneously put into play. ${ }^{95}$

The pianist Catherine Laws describes her experiences in rehearsing and playing Morton Feldman's Palais de Mari in a way that might clarify this concept of virtuality. The piece contains many long rests, during which the pedal is held and the softly played notes slowly decay, creating subtle patterns of resonance. These sounds, so characteristic of the piece, are highly contingent on the construction of the piano and thus differ with each instrument; as might the precise ways in which the pianist is able to play intended dynamics. Laws writes that the performer's normal 'action-perception loop' is interfered with by the behaviour of the instrument, which determines so much of the resulting sound:

In most music, the pianist plays a note or chord, listens to the immediate qualities of that attack (often unconsciously, as part of an embodied process), and prepares for the next, with the actions subtly influenced by the perception of what is heard. However, in Palais de Mari (and much of Feldman's other late music), the 'rest' bars, in which the resonances decay, are not merely spaces between sound events (or in which the performer can prepare the next action) but are materially significant in themselves. How the resonance decays, and how certain overtones fade from prominence and are then reactivated, is of as much interest as the tones activated by the pianist's fingers. ${ }^{96}$

93 Charles Sanders Peirce, 'Virtual', Dictionary of Philosophy and Psychology, ed. James Mark Baldwin (New York: MacMillan, 1902), $763-4$ (p. 763).

94 Gilles Deleuze, Bergsonism, trans. Hugh Tomlinson and Barbara Hammerjam (New York: Zone Books, 1991), 96.

95 Compare my earlier comments on the score as an interface and on relations. Kris Paulsen argues that far from virtual interfaces (a term that she does use in its modern meaning of visual simulation by means of computing) meaning the 'death of the index', the index is a particularly helpful concept for analysing the forms of abductive reasoning and embodied engagement involved in people's understanding of mediated information. She concludes that 'the index is an interface'. Paulsen, 'The Index and the Interface', Representations, 122 (2013), 83-109 (p. 105).

96 Catherine Laws, 'Morton Feldman's Late Piano Music: Experimentalism in Practice', The Practice of Practising, ed. Alessandro Cervino (Leuven: Leuven University Press, 2011), $49-67$ (p. 61). 
These resonant sounds are virtually indicated in the score: they are not to be located in the notes that the pianist is instructed to play, nor in the rests - that is to say, they are not defined by semblance. They are part of the score's efficiency, in that it signifies these resonances by virtue of causation. Crucially, this virtuality intervenes in Laws's familiar protocols for piano playing and leads her to reconsider her role as creative agent in relation to her instrument.

Carolyn Abbate writes that, 'Musical performance challenges notions of autonomy by staging the performer's servitude, even automatism, and upends assumptions about human subjectivity by invoking mechanism: human bodies wired to notational prescriptions. ${ }^{97}$ Many advocates of the performative turn have attempted to rehabilitate the performer as a creative agent, as opposed to his or her neglect by traditional work-centred approaches. However, playing a score is not simply an exercise of agency, it is also a transformation and experimentation of agency. Moseley, in his exploration of the relation between play and music, emphasizes the Gadamerian insight that 'all play is a being played', highlighting the mechanism inherent in play, the degree to which 'reciprocity between the animate and the inanimate world' is a central aspect of musical performance. ${ }^{98}$ Learning to play a piece of music involves a disciplining of the body to make it able to interact with the mechanistic workings of instruments and other forms of technology. Automated musical instruments have raised questions about the agency of musical performers at least since the Enlightenment, being either praised as the perfect performers or feared because they were seen to dehumanize music. ${ }^{99}$ The cylinder notation that has been the most prevalent historical way of automating such instruments not only represents the music 'stored' in its digital code, but more importantly functions as a mechanical means of generating a performance of this music, thus occupying a space 'where notation and fingers become one', as Abbate puts it. ${ }^{100}$ Although she describes this in negative terms, for many commentators throughout history this possibility has been hailed as a perfection of the way in which notation can construct its user, optimizing what Moseley calls the 'systemic coupling of human and mechanical systems' ${ }^{101}$ Rather than opting for either a dystopian or a utopian view of this process, we can see this function of notation in terms of a more general way in which musical performance challenges and reshapes standard accounts of human agency, and ask

97 Carolyn Abbate, 'Music - Drastic or Gnostic?', Critical Inquiry, 30 (2004), 505-36 (p. 508).

98 Roger Moseley, Keys to Play: Music as a Ludic Medium from Apollo to Nintendo (Berkeley, CA: University of California Press, 2016), 4.

99 Adelheid Voskuhl, Androids in the Enlightenment: Mechanics, Artisans, and Cultures of the Self (Chicago, IL: University of Chicago Press, 2013); Rebecca Cypess, "It Would Be without Error": Automated Technology and the Pursuit of Correct Performance in the French Enlightenment', Journal of the Royal Musical Association, 142 (2017), 1-29.

100 Carolyn Abbate, In Search of Opera (Princeton, NJ: Princeton University Press, 2014), 204.

101 Moseley, Keys to Play, 252. 
how musicians are being called upon and constructed as creative agents, and on what basis their subjectivity is perceived as (more or less than) human.

Compare guitar-music notation in tablature with that in staff notation: the former represents the instrument's interface and the actions performed on it, while the latter translates these into the more abstract tonal language of Western music. ${ }^{102}$ The latter, of course, also has to take into account the instrument's build (since what is notated should ideally be technically playable), but this aspect of remediation is rendered 'invisible' through a recourse to tonal theory that presupposes a fundamentally different relation between the musician and their instrument. Such relations have important consequences for the musicians who use these notations. In writing about their collaboration as composer and performer in the creation of a new piece for cello, Fabrice Fitch and Neil Hyde say, "The mobility assumed by the notation offers different interpretations of the "object" it represents. 103 They refer to Helmut Lachenmann's idea that composition is a form of instrument-building, which they take to mean that the composition reshapes the instrument, but also that the instrument reciprocally is part of how the composition is constructed. ${ }^{104}$ But instrumentation does not just construct a musician's relation to their instrument: in doing so, it also mediates the social interaction between musicians, as instrumentation also includes the specification of instrumental roles and patterns of mutual coordination in performance. The abbreviated nature of basso continuo and lead-sheet notations is made possible by their reliance on conventional instrumental roles in performance.

In the previous section I argued that notation and improvisation need not be opposed to each other, and that the idea of notation necessarily inhibiting a performer's agency is contingent on particular discursive practices. I now suggest more broadly that notation can be seen as providing opportunities for developing and exercising creative agency by the way it negotiates and constructs protocols of musical performance. Braille notation is a good example of a form of notation that affords rather than opposes the exercise of agency, as well as the idea that improvisation can be found precisely in the construction of stability. The visually impaired pianist

102 Obviously, staff notation can be used to write down non-tonal, non-Western music. Rather, the point is that in order to read it a guitarist needs to be familiar with some basic aspects of the diatonic system, while tablature requires familiarity only with the frets and strings on a guitar's neck.

103 Fabrice Fitch and Neil Heyde, "Recercar": The Collaborative Process as Invention', TwentiethCentury Music, 4 (2007), 71-95 (p. 89).

104 Jonathan De Souza explores this idea in the compositions and arrangements of Bach. Arrangements, of course, simultaneously remediate scores and instruments. Peter Szendy describes arrangements as offering the ability of listening to listening, and writes that it is 'a mutation of bodies - of the instrumental body as well as the interpretative body - that opens new possibilities to translate music to the letter'. Jonathan De Souza, Music at Hand: Instruments, Bodies, and Cognition (Oxford: Oxford University Press, 2017), 109-44; Peter Szendy, Listen: A History of our Ears (New York: Fordham University Press, 2008), 55-6. 
and former Royal College of Music student Tomoko Endo describes why she learnt to read Braille music: 'I need to be able to read music as well, so that I can interpret the pieces on my own without the risk of copying someone else's interpretation. ${ }^{105}$ Clearly, learning to read the music rather than copying it by ear serves an emancipatory potential as it makes it possible for Endo to develop her own voice and identity as a musician. Braille music builds on protocols that are highly familiar to the blind and visually impaired, and remediates them to allow them to read music. The physical abilities of a musician constrain the possibilities of developing such protocols, and thus guide the ways in which remediation takes place. However, the way in which Braille music accommodates the sensory perception of its users also has important practical consequences for the negotiation of the relation between text and performance. In using Braille notation, reading and playing are necessarily asynchronous - there is no such thing as 'sight-reading', because musicians need their hands to read as well as play their instruments. This is also the case for singers, as in Braille there is no way to 'align' lyrics and music notation, and the two need to be read separately. This points to the necessary improvisation in performing from Braille, as simultaneously sounding 'parts' have to be read separately and can only be joined together in performance this is also true for pianists and other keyboard players who, for instance, have to read and memorize contrapuntal lines separately before combining them. As Shersten Johnson points out, Braille notation makes clear how scholarly conceptions of musical understanding and analysis (she discusses Schenkerian analysis in particular) have been shaped by the epistemic affordances of staff notation. ${ }^{106}$

\section{Conclusion}

I have discussed three ways in which notations can be seen to compose different musical worlds, and have suggested various ways in which such processes put into play notions of musical creativity, culture, agency and knowledge. To conclude, I would like to draw attention once more to the relationality of notation in the definition I have proposed. As the anthropologists Amiria Henare, Martin Holbraad and Sari Wastell have suggested, we might take people's engagement with things not just as a subject to be studied, but heuristically, as a way to consider how we as academics

105 Martin Wainwright, 'Prima Vista Scores a Musical Hit for Visually Impaired People', The Guardian, 15 February 2011, Society section, <https://www.theguardian.com/society/2011/feb/15/primavista-musical-visually-impaired> (accessed 8 March 2019).

106 Shersten Johnson, 'Understanding is Seeing: Music Analysis and Blindness', The Oxford Handbook of Music and Disability Studies, ed. Blake Howe, Stefanie Jensen-Moulton, Neil Lerner and Joseph Strauss (Oxford and New York: Oxford University Press, 2016), <https://oxfordindex.oup.com/ view/10.1093/oxfordhb/9780199331444.013.7> (accessed 24 April 2019). 
define things in studying them. ${ }^{107}$ Holbraad and Pedersen, commenting on the work of Strathern, suggest that since a thing is only what it is because of its relation to other things, it is 'always more and less than itself' - and hence that a study of things is always a study of comparisons. ${ }^{108}$ We have seen this repeatedly in the examples given above. The musical ontologies of notation cultures may not be restricted to musical practice, but may be part of broader considerations about the role of human agency in the world - Cook writes that music is 'not just a metaphor but a metonym of social interaction'. 109

Such considerations also underlie Georgina Born's call to move 'beyond the practice turn' in recent music scholarship, towards what she and Cook have called a relational musicology. This perspective, like the methodology I have outlined here, is fundamentally comparative; it displays, in Born's words, 'a bullish affirmation of the benefits of aspiring to an always impossible analytical totality. ${ }^{110}$ This comparativism, however, does not just aim to subsume particular examples under a general, objective and universal framework, but acknowledges its own situatedness and partiality. ${ }^{11}$ Comparison is thus not a matter of subsuming things under increasingly abstract predicates, but of moving along different 'planes' of music's social mediation. ${ }^{112}$

If to study a thing is to make a comparison, then much of historical musicology and music analysis has always implicitly been the comparative study of notation cultures. Moreover, with its own investment in notation, for instance through the production of scholarly editions or through melography and cantometrics, music scholarship has itself always been a collection of notation cultures. The description of the compositional work of notation in different musical practices may thus also help to reflect on the worlds that music scholarship itself has composed. The relation between notation and performance, between text and act, has long been a topic of musicological consideration. The study of notation cultures turns this relation from a subject of philosophical speculation into one of ethnographic and historical investigation. Such a comparative approach may show how notation is embedded in musicking practices; how musical knowledge is constructed through visual and symbolic representation; how notions of entextualization, codification, remediation and contextualization construct particular ways of imagining creative agency; how

107 Amiria Henare, Martin Holbraad and Sari Wastell, 'Introduction', Thinking Through Things, ed. Henare, Holbraad and Wastell, 1-31.

108 Martin Holbraad and Morten Axel Pedersen, 'Planet M: The Intense Abstraction of Marilyn Strathern', Anthropological Theory, 9 (2009), 371-94 (pp. 374-5).

109 Cook, 'Anatomy of the Encounter', 196.

110 Born, 'For a Relational Musicology', 224.

111 Compare Donna Haraway, 'Situated Knowledges: The Science Question in Feminism and the Privilege of Partial Perspective', Feminist Studies, 14 (1988), 575-99 (p. 597, n. 5), and Marilyn Strathern, Partial Connections (New York: Rowman Altamira, 2004), 31-2.

112 Georgina Born, 'Music and the Materialization of Identities', Journal of Material Culture, 16 (2011), 376-88. 
such concepts of agency also institute economic and juridical notions of ownership and property; and how musical ontologies map out such epistemological, ethical, social and cultural considerations. In other words, through a study of notation cultures, we might discover new musicologies.

\section{ABSTRACT}

The ubiquity and diversity of notational practices in music suggest that notation is a significant part of human beings' musicking behaviour. However, it is difficult to address its function since the usual conception of notation in music scholarship is at odds with studying performance in the first place. This article presents a methodological outline for an ethnomusicology of music notation by investigating the musicality of notation not in terms of its representation of musical structures, but in terms of its mediation of the social and creative agency of musicians. It is suggested that, rather than detracting from musical reality, notation composes musical cultures. This constructive work is simultaneously ontological and ethical. It is described in terms of three distinct processes, namely mobilization, entextualization and remediation. In doing so, this article presents an interdisciplinary approach to a topic that has traditionally defined the disciplinary centre of music scholarship. 